\section{Case Reports in Dermatology}

Case Rep Dermatol 2017;9:184-189

DOI: $10.1159 / 000480722$

Published online: October 4, 2017
The Author(s)

Published by S. Karger AG, Basel www.karger.com/cde

This article is licensed under the Creative Commons Attribution-NonCommercial 4.0 International License (CC BY-NC) (http://www.karger.com/Services/OpenAccessLicense). Usage and distribution for commercial purposes requires written permission.

\title{
Nevus Comedonicus: Case Report
}

\author{
Renata Pinto Fernandes Timbó Maria Kátia Gomes \\ Eduardo Mastrangelo Marinho Falcão Marcia Ramos-e-Silva
}

Sector of Dermatology and Post-Graduation Course, University Hospital and School of Medicine, Federal University of Rio de Janeiro, Rio de Janeiro, Brazil

\section{Keywords}

Nevus · Hamartoma $\cdot$ Nevus comedonicus

\begin{abstract}
Nevus comedonicus is a rare cutaneous anomaly, characterized by the clustering of papules with firm, blackened horny buffers. It in general has a zosteriform pattern and affects both genders equally. In some patients, there is formation of cysts, abscesses, and fistulas, aggravating its psychosocial impact. The association with extracutaneous lesions characterizes the nevus comedonicus syndrome. Despite several therapeutic options, the result is unsatisfactory in most cases. We report the case of a man with an exuberant congenital lesion, affecting the left suprascapular region, arm, and forearm.

(C) 2017 The Author(s)

Published by S. Karger AG, Basel
\end{abstract}

\section{Introduction}

Nevus comedonicus is a rare hamartoma of the pilosebaceous unit, first described by Kofmann in 1895 [1, 2]. In most cases, it has been present since birth but may also develop later, usually before the age of 10 years, without racial or sexual preference. When appearing in adult age, although rare, it is frequently associated with irritation or trauma [3].

Its occurrence entails the unregulated growth of the mesoderm portion of the pilosebaceous unit. The invaginations of the epithelial line, unable to form mature terminal hairs and sebaceous glands, accumulate a horny and softened ostial product, resulting in a plug [3]. 
It features bundles of papules and dilated follicular openings containing epidermal residues and firm pigmented horny plugs, similar to comedones [4]. The lesions typically present a linear or zosteriform distribution, but extensive areas have already been described, including with bilateral involvement [5]. The most frequently affected sites are the face, trunk, neck, and upper limbs. It may affect areas without hair follicles, such as the palms, soles, and the glans penis. Scalp involvement is rare [1]. There may be associations with other skin lesions or abnormalities of the central nervous, musculoskeletal, and ocular system [6].

We present a typical case of nevus comedonicus in a man with relevant psychosocial repercussion.

\section{Case Report}

A 43-year-old black man who was a janitor, born and living in Rio de Janeiro, was referred to our department due to a lesion he had since birth in the left suprascapular region with progressive growth until the age of 5 years, extending along the left arm and forearm. The clinical aspect and extension of the lesion caused a relevant psychosocial repercussion, mainly during adolescence, leading him to prefer the use of long-sleeve shirts, to avoid beaches and swimming pools and the practice of activities without a shirt, also interfering with his affective relationships. There were some episodes of infection, associated with the manual removal without the due asepsis, entailing the development of cysts and pustules that were treated with antibiotic therapy; but these infections did not continue in adult life.

At dermatologic examination, bundles of dilated hair follicles were observed, filled with dark colored plugs, presenting a linear distribution in the left suprascapular region (Fig. 1), left arm (Fig. 2, 3), and left forearm (Fig. 3, 4). He did not present other cutaneous lesions or alterations to bones, nerves, or eyes.

Based on the history and typical features of the lesion, it was clinically diagnosed as nevus comedonicus. Due to the extension of the lesion and the possibility of its turning into an unaesthetic scar, the patient chose a noninvasive therapy, but the result after application of $0.1 \%$ retinoic acid cream was unsatisfactory, leading to suspension of the treatment.

\section{Discussion}

Nevus comedonicus is a rare problem with an estimated occurrence of 1 case in every 45,000-100,000 individuals [2, 6]. According to Inoue et al. [7], only 200 cases were described until the year 2000. The disease can be divided into 2 groups: (1) formation of horny comedone-like plugs occurs without suppurative, acneiform prevalence; and (2) cystic formations, with recurrent infections, fistulas, abscesses, and scars, are the prevailing findings $[4,6]$.

Cestari et al. [8] believe that some cases may be exacerbated during puberty due to inflammatory alterations associated with an increase in eccrine and sebaceous secretions. It can also be associated with other cutaneous abnormalities, such as epidermolytic hyperkeratosis, trichilemmal cysts, epidermal cysts, and other cutaneous tumors.

Nevus comedonicus syndrome is characterized by extracutaneous manifestations associated with nevus comedonicus. The main alterations are ocular (congenital cataract), osteal (scoliosis, vertebrae fusion, spina bifida, and absence of fifth finger), and neurologic (mental 
Timbó et al.: Nevus Comedonicus: Case Report

retardation, convulsions, and corpus callosum dysgenesis). It can also accompany the Klippel-Trénaunay and Sturge-Weber syndromes [4, 5].

The diagnosis is predominantly clinical, with biopsy only indicated in rare cases, especially in group 2. The histopathologic exam evidences an epidermis with dilated follicular openings, filled with horny material. The sebaceous glands and hair follicles are usually absent or rudimentary [6]. The differential diagnosis should be made with dermatoses presenting comedones or lesions resembling neonatal acne, comedonal acne, chloracne, family dyskeratotic comedones, and porokeratotic ostial nevus [3, 4, 6].

Nevus comedonicus should be treated not only due to cosmetic aspects but also in order to prevent complications from infections with suppuration and residual scars. However, as with other epidermal nevi, its treatment is a challenge. The use of topic keratolytics and procedures, such as salicylic acid, dermabrasion, and manual extraction, can be useful but does not cure. Complete surgical excision seems to be the most appropriate treatment; however, the extension and location can often limit the use of this procedure. Isotretinoin is usually not recommended as a long-term therapy, although it can provide great benefit in preventing cysts. Antibiotic therapy is useful for secondary infections. There are also reports of use of $\mathrm{CO}_{2}$ lasers $[6,7]$.

\section{Conclusion}

The patient presented a nevus comedonicus classified as group 1, presenting with a predominance of nonsuppurative lesions and an absence of extracutaneous manifestations. We emphasize the exuberance of the lesion and relevance of the psychosocial impact in our patient. We also highlight the therapeutic challenge, despite several treatment modalities described in the literature.

\section{Statement of Ethics}

The authors state that the patient gave his informed consent.

\section{Disclosure Statement}

The authors have no conflicts of interest. There was no funding for this article.

\section{References}

1 Garcia LC, Cabeda LF, Garcia R, Borile G: Nevus comedonicus: surgical treatment. Rev Soc Bras Cir Plast São Paulo 2000;15:7-14.

2 Kaliyadan F, Bhimji S: Nevus comedonicus; in StatPearls. Treasure Island, StatPearls Publishing, June 12, 2017. https://www.ncbi.nlm.nih.gov/books/NBK441903/ (accessed August 10, 2017).

3 Requena L, Requena C, Cockerell CJ: Benign epidermal tumors and proliferations; in Bolognia JL, Jorizzo JL, Schaffer JV (eds): Dermatology, ed 3. Philadelphia, PA, Elsevier Saunders, 2012, pp 1795-1815.

4 Taborda PRO, Taborba VBA, Virmond MC: Nevus comedonicus: a propos of a case. An Bras Dermatol 1997;72:459-463.

-5 Yadav P, Mendiratta V, Rana S, Chander R: Nevus comedonicus syndrome. Indian J Dermatol 2015;60:421. 


\section{Case Reports in}

6 Tchernev G, Ananiev J, Semkova K, Dourmishev LA, Schönlebe J, Wollina U: Nevus comedonicus: an updated review. Dermatol Ther (Heidelb) 2013;3:33-40.

7 Inoue Y, Miyamoto Y, Ono T: Two cases of nevus comedonicus: successful treatment of keratin plugs with a pore strip. J Am Acad Dermatol 2000;43:927-929.

-8 Cestari TF, Rubim M, Valentini BC: Nevus comedonicus. Case report and brief review of the literature. Pediatr Dermatol 1991;8:300-305.

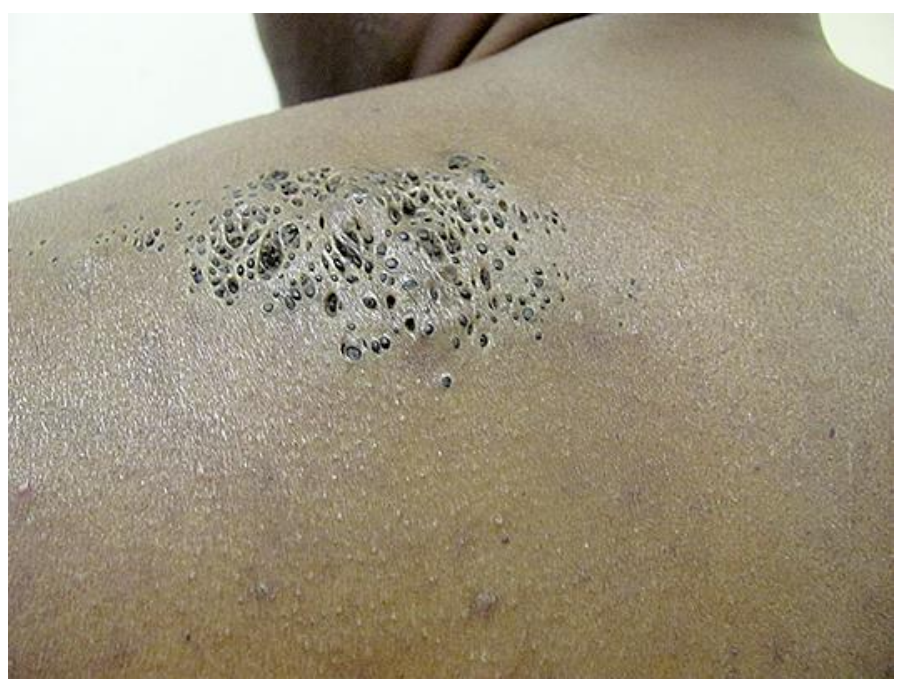

Fig. 1. Lesion on the left suprascapular region. 


\section{Case Reports in Dermatology}

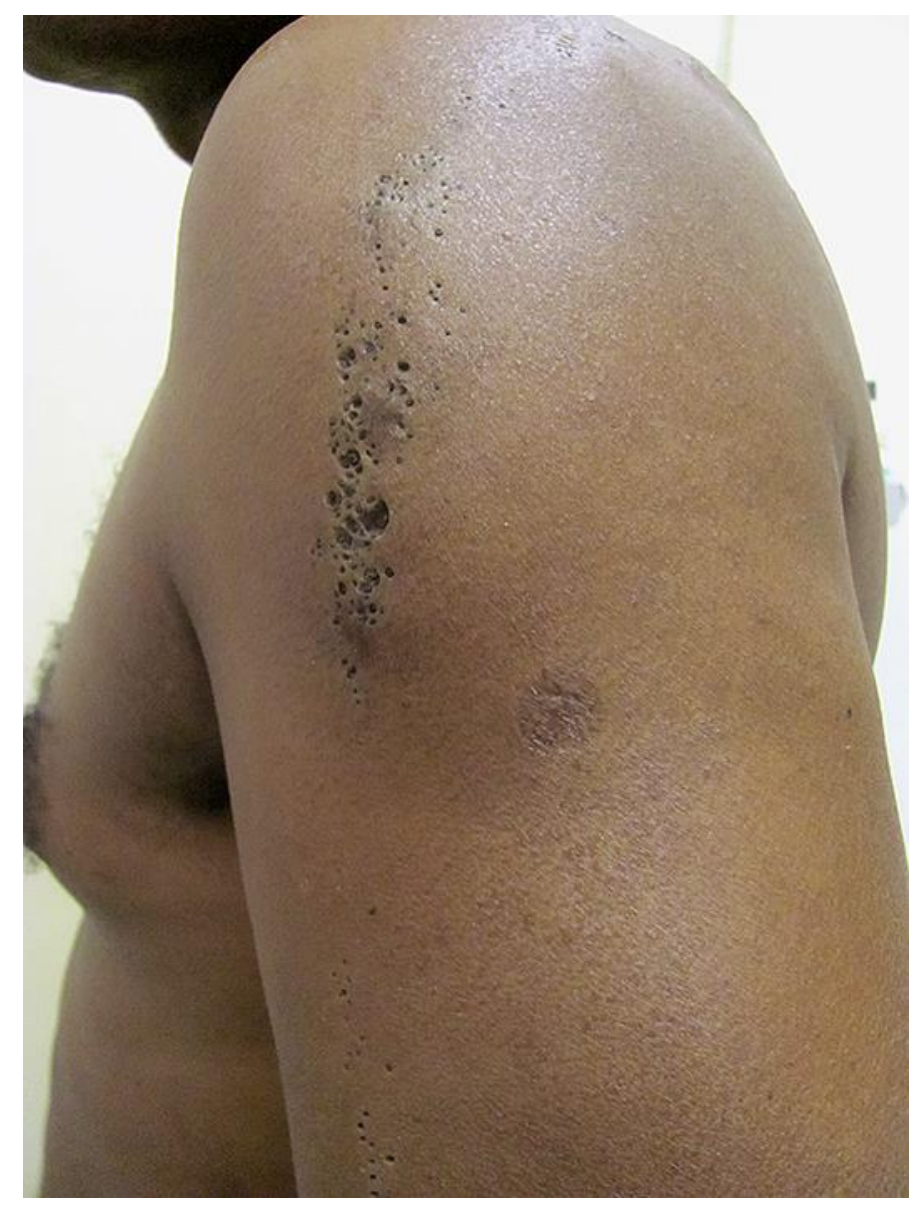

Fig. 2. Lesion on the left arm. 


\section{Case Reports in Dermatology}

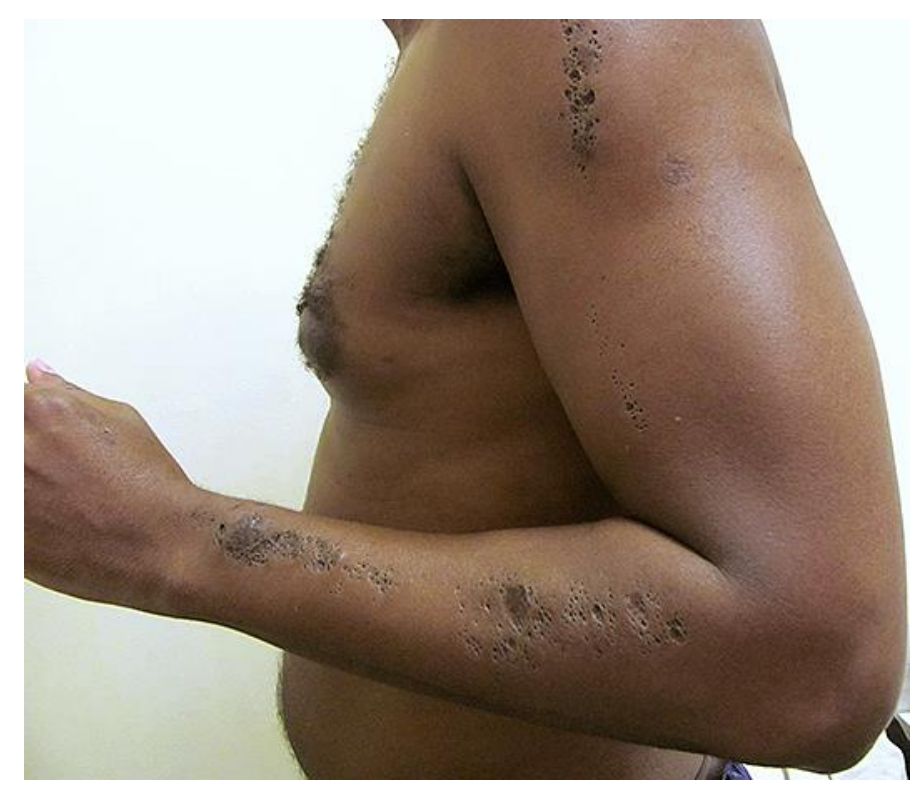

Fig. 3. Lesion on the left arm and forearm.

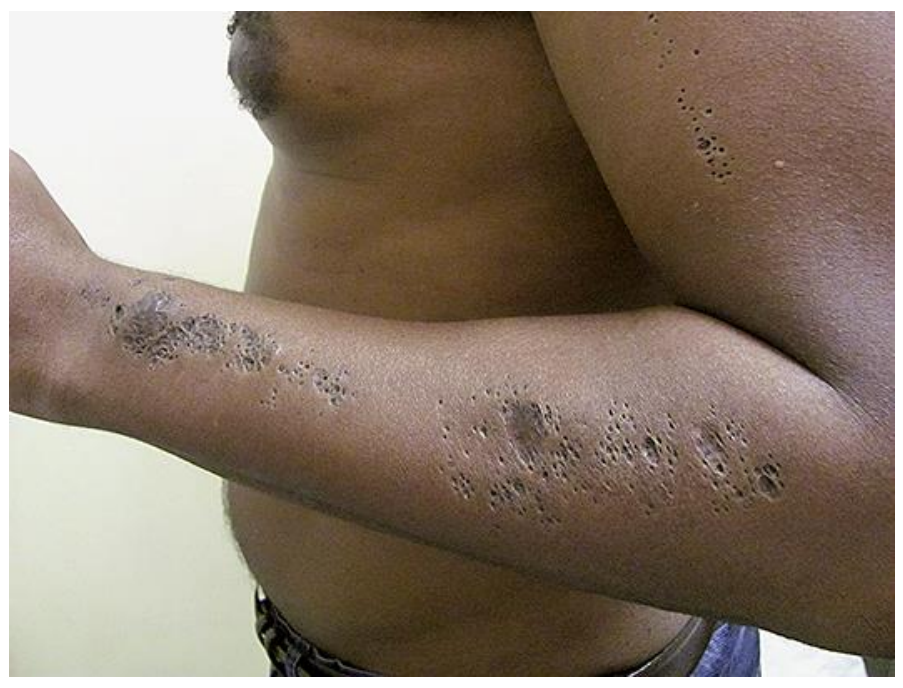

Fig. 4. Detail of the lesion on the left arm. 